\title{
Ficción, historia y mito en El río sin orillas de Juan José Saer
}

\section{Fiction, history and myth en El rio sin orillas of Juan José Saer}

\author{
Daniel Samperio Jiménez \\ El Colegio de México, México
}

Resumen: Este trabajo se ocupa de la confrontación entre ficción e historia en El río sin orillas de Juan José Saer con base en un examen de la incursión del autor en la autobiografía y la non-fiction. Éstas reflejan una intención de Saer por bordear los límites entre lo irreal y lo verificable para buscar resquicios para la ficción y, al final, encontrar el mito personal como cuestionamiento esencial de la historia.

Palabras clave: Saer, narración, ficción, historia, mito.

Abstract: This work is about the comparison between fiction and history in El río sin orillas of Juan José Saer based on an exam of generic reprocessing operations practiced by the author with the autobiography and the non-fiction. These reflect an intention to Saer skirting the boundary between the unreal and the verifiable to search for chinks for fiction and, at the end, find the myth as essential contraposition of the history.

Keywords: Saer, Narration, Fiction, History, Myth. 
Frio sin orillas (1991) refiere el descubrimiento de una región

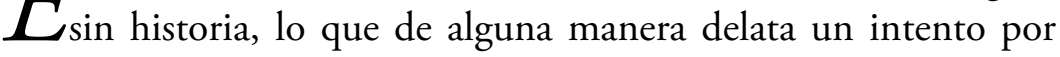
escribirla. Entre sus sentidos, el libro supone un tratado histórico de todo cuanto se relaciona con el río, el cual Saer toma como metáfora de su propio país. Pero se trata de la escritura de un "tratado imaginario", por cuyo paradójico subtítulo se perfila un libro marcado por lo ficcional. En él, el escritor -quien plantea su texto como un relato- despliega una estrategia que en el fondo tiene el objetivo de dar cauce a la ficción, aunque sin faltar a las restricciones de índole histórica que ha impuesto a su ejercicio narrativo. En las primeras páginas, el autor es claro en afirmar que "en este libro no hay un solo hecho voluntariamente ficticio. Todo lo que se cuenta, proveniente de libros, de referencias orales y de experiencias personales, ha efectivamente acontecido" (Saer, 1991: 18). Por ello, el autor elige la non-fiction y el discurso autobiográfico para emprender su relato, puesto que ambos moldes genéricos se instalan desde lo verificable y la comprobación histórica.

Si hay pueblos y regiones en el mundo que por su relativo aislamiento geográfico han entrado con retraso de siglos a la historia, si, por ejemplo, la inmensa llanura rusa en la obra de Herodoto apenas aparece habitada por "extraños argireos, pacíficos y arborícoras, que eran calvos de nacimiento" (Krakowski, 1956: 36), la región entrerriana donde confluye el Paraná y el Uruguay representa uno de esos últimos lugares que registra la geografía y la historia (occidental). Como todo límite del mundo desde cierta perspectiva, es natural que en un inicio se haya hablado de esta región tras un velo de misterio y en los términos de una verdadera tierra incógnita.

Nada más esperanzador para un narrador como Juan José Saer que contar con una clase similar de selva espesa de lo real. Entre otras cuestiones de índole literaria, política y cultural, el escritor 
relata en El rio sin orillas. Tratado imaginario el paulatino descubrimiento de ese inmenso espacio sin geografía y sin historia. El libro, que para la mayoría de la crítica constituye un largo ensayo, no obstante, jamás abandona la vena narrativa. El autor plantea su texto desde la perspectiva de la narración y en función de ella lo construye. En uno y otro lado del texto, el "narrador" no deja de referirse a su relato.

Para Saer, la narración trascendía los moldes genéricos, como el de la novela; ${ }^{1}$ la concebía como un organismo vivo en constante transformación. En un texto como El río sin orillas, la narración se plantea también como un ejercicio ensayístico que relaciona excepcionalmente la memoria personal con la historia política y social de la región. En este sentido, Saer pertenece a una tradición singular en el marco de la literatura argentina (Borges, Macedonio, Piglia) que establece puentes entre la ficción y el ensayo.

La manera en que la narración bordea lo ensayístico tiene mucho que ver con la elección de la non-fiction y el discurso autobiográfico como moldes genéricos que verifican y autorizan los hechos relatados. En este orden, lo verificable desempeña un relevante papel, ya que el relato queda encomendado a este elemento por entero, por lo que está libre de cualquier ficción premeditada. Cabe aclarar esto último pues la diferencia con respecto a cierta ficción no premeditada abre un camino al autor para cumplir sus expectativas de restituir el elemento ficticio bajo la categoría de ficción involuntaria y verificable:

1 “Toda novela es narración, pero no toda narración es novela. [...] Rompiendo el molde demasiado rígido de los géneros, de las escuelas, de los contenidos, de las supuestas técnicas que enorgullecen a tantos escritorzuelos, la narración se transforma, incesante, y son sus transformaciones las que le otorgan, a cada momento histórico, su frescura y su necesidad" (Saer, 2005: 45-46). 
La ausencia de ficción debe entonces entenderse en el sentido estricto de ficción voluntaria al que acabo de aludir, y ella resume mi única probidad, y si bien se trata de un límite constrictivo, no deja de tener su lado estimulante, ya que me obliga a intentar la elaboración de un texto narrativo en el que, faltando el elemento ficticio que a menudo preside su organización, estoy obligado a replantearme mi estrategia de narrador (Saer, 1991: 19).

La estrategia está proyectada para encauzar la narración no a través de la ficción que se asocia generalmente con hechos inventados o imaginados, sino por medio de otra dimensión de lo ficcional. De modo que la incursión en la non-fiction y el discurso autobiográfico representa para Saer una perfecta coartada.

\section{Discurso autobiográfico}

Como texto que apela a un discurso autobiográfico, el escritor no sólo vuelve sobre sus propias huellas en la región, sino que introduce sus íntimas sensaciones sensoriales e impresiones como elemento autorizador del texto. Basta observar la imagen inicial, en la que el narrador, Saer en tanto escritor, a bordo del avión en vuelo reencuentra el mito personal:

De pronto dejé de estar en el avión para encontrarme en alguna remota mañana de Serodino, en mi pueblo, una de esas mañanas soleadas y desiertas de los pueblos de la llanura, de modo que me vino, durante varios minutos, una impresión de unidad, de intemporalidad y de persistencia. Durante esos instantes el ritual, desgastado por la costumbre, recuperó, en la situación más adversa, el mito inextinguible (Saer, 1991: 15).

Vivencias de este tipo aparecen en el texto respaldadas por el perfil autobiográfico que adquiere la narración. Esto resulta espe- 
cialmente significativo en Saer, para quien la vivencia primigenia es constitutiva de lo real y para quien lengua y mundo conforman una unidad entrañable. ${ }^{2}$ En esa vuelta al origen, el narrador encuentra un puente hacia una dimensión hondamente afectiva. Sin embargo, no es tan fácil el reconocimiento en medio de ese espacio emocional puesto que: "El mundo es difícil de percibir. La percepción es difícil de comunicar. Lo subjetivo es inverificable" (Saer, 2005: 44).

De este modo, la vivencia para Saer no pareciera estar suficientemente autorizada para dar cuenta del hecho verificable. Con todo, como ésta es registrada mediante el discurso autobiográfico, no deja de tener autoridad en El río sin orillas, aunque sea difícil de verificar, puesto que, como autobiografía que es, bajo el texto subyace un pacto referencial. Sin dejar de lado la identificación entre el narrador y autor del texto, "por más que en su relación con la historia (lejana o casi contemporánea) del personaje, el narrador se equivoque, mienta, olvide o deforme, error, mentira, olvido o deformación adquirirán, si se los discierne, el valor de un aspecto entre otros, de una enunciación que, en sí misma, sigue siendo auténtica" (Lejeune, 1994: 40). Con ello, el autor inevitablemente abre un resquicio para la ficción en una trama textual que se supone compuesta de elementos verificables por entero. Ello porque se trata, ante todo, de una ficción involuntaria que no está reñida con que sea verificable, dado el pacto referencial que valida su autenticidad. De este modo aquella ficción que se encauza por medio del discurso autobiográfico, aún con que sea difícil de comunicar (por

2 "Y sin embargo, estamos constituidos en gran parte por el lugar donde nacemos. Los primeros años del animalito humano son decisivos para su desarrollo ulterior. La lengua materna lo ayuda a constituir su realidad. Lengua y realidad son a partir de ese momento inseparables. Lengua, sensación, afecto, emociones, pulsiones, sexualidad: de eso está hecha la patria de los hombres, a la que quieren volver continuamente y a la que llevan consigo donde quiera que vayan. La lengua le da a esa patria su sabor particular" (Saer, 2005: 37). 
ser siempre subjetiva, espacios de memoria y experiencia), tiene cabida en un texto que se restringe a hechos acontecidos efectivamente por esta misma razón: la vivencia puede ser difícilmente comunicable, un equívoco, una deformación, incluso una mentira, pero jamás inauténtica.

\section{Non-fiction}

Dentro de la búsqueda constante de caminos para la narración, el autor siempre había tenido en la mira otra clase de géneros como la novela policial -cuya resultante es La pesquisa (1994) - en vistas de renovar el relato. Esto justamente cuando esas formas genéricas trascienden su alcance original. ${ }^{3}$ De modo que, por igual, la pertenencia de la non-fiction a esos géneros abre vías a Saer para su relato-río.

La non-fiction tiene un punto de partida claro de la mano de Rodolfo Walsh con Operación masacre (1957), publicada varios años antes de la obra de Truman Capote (In Cold Blood, 1996), que se reconoce como pionera del género en el mundo anglosajón. Su aparición, particularmente en Argentina, coincide con un periodo histórico de torturas y desapariciones. Saer, en efecto, abunda sobre ello en la sección "Invierno" del libro, donde la narración testimonia el horror de la violencia de Estado.

El hecho de que el autor tome como punto de partida la non-fiction delata hacia dónde quiere llegar o qué busca plantear con el texto. Saer ya había reflexionado sobre ello en términos del

3 "Puede decirse que históricamente, la noción de género se ha ido circunscribiendo [la poesía, la novela, el ensayo]. Podríamos también hablar de nuevos géneros, como la novela policial, la de ciencia ficción, el teatro de bulevar, etcétera... Pero, en tanto que géneros, pertenecen a la infraliteratura. Es justamente cuando superan los esquemas del género, que pueden volverse literatura" (Saer, 2005: 41-42). 
criterio de veracidad que rige la non-fiction. Cuando en el ensayo "El concepto de ficción" señala que ciertamente la supresión cuidadosa de todo elemento ficticio no es criterio de verdad, Saer tiene en mente la non-fiction, género cuya especificidad se basa en la exclusión del rastro ficticio. Para un escritor, a quien "el concepto mismo de verdad es incierto" (Saer, 2004: 10), trabajar especialmente en los moldes de un género como la non-fiction representó la oportunidad idónea para llevar a cabo su estrategia de narrador de El río sin orillas. Si la supresión del elemento ficticio no significa criterio de veracidad y la esencia de la non-fiction es la exclusión de lo ficcional, entonces la incursión en el género permitiría al autor partir de cierta premisa para poner en duda la noción de veracidad $y$, acaso, lograr deslizar la ficción en donde, en principio, estaría excluida.

De esta manera, también en la non-fiction el escritor abre otro resquicio donde puede integrar la ficción, involuntaria y verificable, en el texto. No es casual que, dentro de esta línea, la referencia a libros y relatos de viajeros adquiera una dimensión especial. Se trata de la relación de las sucesivas expediciones a la región: la de Juan Díaz de Solís, la de Sebastián Gaboto, la de Pedro de Mendoza. Relatos que como documentos historiográficos constituyen fuentes autorizadas, pero que también llegan a recordar obras imaginativas en la misma tónica de El entenado (1983) del propio Saer o de las últimas páginas de Zama (1956) de Antonio Di Benedetto. En ambas novelas, sin prescindir del elemento histórico o mejor aún en gran parte a causa de él, la ficción se abre camino entre sucesos cuya realidad comienza a ser cuestionable. Son ficciones de un mundo alucinante en las que se podría inscribir la obra fílmica de Werner Herzog, Aguirre, la ira de Dios, en tanto que plantea el delgado lindero entre la realidad y la ficción que un grupo de expedicionarios bordea en medio de la selva amazónica y abandonados a su propia locura. 
En El río sin orillas, se puede observar, igualmente, al narrador describir la existencia de Pedro de Mendoza en la región, casi cual si se tratara de otro Lope de Aguirre: "La tierra vacía y chata en la que encalló, tan propicia al delirio aun en los días más calmos de la existencia, no hizo más que acrecentar los espasmos de su propia fiebre, que era terriblemente verdadera y que, desde la partida misma de España, lo enredó en espejismos, en incongruencias, en recelos paranoicos y en caprichos sangrientos" (Saer, 1991: 69). En pasajes como éste, la realidad que se narra desde lo verificable entra en terrenos de la imaginación y pone en duda si no se trata, en efecto, de sucesos ficticios.

Esto no es nada nuevo para Saer, quien solía leer a los historiadores clásicos como escritores de ficción, ${ }^{4}$ los cuales se proponían escribir tratados que estuvieran basados en criterios objetivos y racionalistas. ${ }^{5}$ Como en éstos, en el tratado imaginario de Saer la ficción involuntaria se hace presente inevitablemente. No es casual en un libro que, al igual que esas historias antiguas, pretende dar cuenta de una realidad desconocida y extraña. De ahí que Saer volviera recurrentemente a esa clase de textos, puesto que en ellos el narrador, como en El río sin orillas, se enfrenta a espacios sin historia y faltos de una geografía precisa.

En este orden, Saer abreva de toda una tradición literaria, la Crónica de Indias, en cuyos máximos exponentes, como Bernal Díaz del Castillo, escritores como Alejo Carpentier o Juan Rulfo

4 "Los leo [Tácito, Suetonio, Plutarco] como grandes escritores de ficción, y no me interesa saber si lo que cuentan es verdadero o no. [...]Para mí son textos de ficción; tampoco me interesa saber qué fue lo que pasó” (Saer, 1995: 81).

${ }^{5}$ Es Tucídides el caso más representativo: "Poseía una visión radicalmente distinta de la historia, contraria a las interpretaciones legendarias o partidistas, y se propuso escribir, según señaló en el prefacio a su tratado, una crónica definitiva de la guerra, sobre principios de fidelidad e imparcialidad, que sobreviviera el paso de los ańos y permitiera extraer conclusiones útiles para todo tiempo" (Tucídides, 1989). 
reconocieron las primeras novelas y obras de ficción escritas en América. Al igual que ocurre con la autobiografía, la tradición de este tipo de relatos (originalmente históricos) sirve perfectamente al narrador para salvar la ficción sin apartarse de lo verificable, que en este caso es autorizado por el relato histórico. Si bien dentro del esquema de construcción de la non-fiction abrevar en aquél conlleva una serie de fuentes y testimonios de utilidad para la Historia, la Crónica de Indias supone una tradición que representa, entre otras cosas, una excepcional obra de imaginación.

\section{El mito personal}

Como se ha podido ver, El río sin orillas cuenta con un narrador que demuestra su probidad al apegarse a un par de géneros, cuya especificidad consiste en excluir cualquier elemento de ficción voluntaria. Más aún, mediante las reglas del juego de estos géneros, el narrador encuentra resquicios para, inevitablemente, dar cauces a lo ficcional. Sin embargo, con ello, el narrador no sólo comprueba su probidad para sacar adelante la ficción (involuntaria) sino, incluso, demuestra que la ficción está más allá de lo verificable.

En "El concepto de la ficción", Saer ya resaltaba que la ficción, desde sus orígenes, había sabido emanciparse tanto de las cadenas de lo que tiene que ser verificado como de la verdad; en cambio se escribe -afirma el autor- "justamente para poner en evidencia el carácter complejo de la situación” (Saer, 2004: 11). Para Saer, no se trata de reivindicar "ni lo falso ni lo verdadero como opuestos que se excluyen, sino como conceptos problemáticos que encarnan la principal razón de ser de la ficción" (Saer, 2004: 15). De forma que la emancipación de lo ficcional se corresponde, precisamente, con su capacidad para problematizar lo verificable y lo que se tiene por verdadero. 
Cabe preguntarse por el sentido de llevar a cabo una comprobación semejante de la ficción y su no verificabilidad en El río sin orillas por medio de la incursión del narrador en el discurso autobiográfico y la non-fiction. Para ello habría que reflexionar que si el concepto de verdad siempre resulta problemático e incierto, pues comporta elementos contradictorios y dispersos, si acaso es ineludible el problema de una supuesta verdad objetiva, es porque del otro lado existe la ficción que da cabida a toda la subjetividad posible. Pero el objetivo de ésta, así como no afirma, tampoco es el de negar simplemente la verdad de los hechos. Representa principalmente el medio más apropiado para tratar las relaciones complejas entre la realidad y lo irreal. Ella no pretende usurpar el puesto de la verdad, ni "solicita ser creída en tanto que verdad, sino en tanto que ficción” (Saer, 2004: 12). Por lo que esa tentativa de Saer para comprobar la existencia de la ficción por medio del discurso autobiográfico y la non-fiction tiene mucho que ver con confrontar y adelgazar la línea entre la realidad y la ficción.

El subtítulo del libro cifra esa intención con un oxímoron, puesto que efectivamente Saer no se propone una historia objetiva del río como tampoco un libro de ficción voluntaria. Al contrario, le interesa escribirlo desde esa zona de tránsito donde la realidad es problematizada por la ficción involuntaria. No se trata de que, al someterse a los lineamientos de la autobiografía y la non-fiction, todo lo que el narrador relata sea creído abiertamente por el lector, sino en el sentido de que no afirma ni niega una realidad. Por ello, el narrador se ocupa con ahínco en construir una narración más como un objeto que puede suscitar todo tipo de apreciaciones, que como un discurso unívoco. ${ }^{6}$ Esto es, ante todo, el objeto de la

${ }^{6} \mathrm{El}$ concepto de objeto contrapuesto al de discurso es fundamental en Saer: "Siempre resultará más seguro considerar la narración como un objeto autónomo, un fin en sí de cuya sola realidad como objeto debemos extraer todo su sentido" (Saer, 2000: 43). 
ficción que se instala en una supuesta realidad para incomodarla y replantearla.

Sin embargo, tras esa comprobación de la ficción hay una tentativa ulterior para Saer, puesto que en la delgada frontera entre realidad y ficción el narrador sitúa un elemento central de todo el libro: el mito personal. Puede situarlo porque, justamente, éste se halla en un lindero muy tenue de ficción involuntaria, donde representa un suceso verificable y, al mismo tiempo, un elemento ficcional.

En la incursión entre el discurso autobiográfico y la non-fiction, el narrador se acerca más al mito personal por medio del primero. Se ha visto cómo la vuelta al origen lleva al narrador a referir la experiencia primigenia, donde lengua y mundo constituyen unidad inseparable para el sujeto. La crítica ha destacado el papel de la lengua en El río sin orillas: "El recorrido que realiza Saer [...] apunta a reconformar su lengua, su patria, su casa a partir de poner en lenguaje la configuración de un territorio real, simbólico e imaginario" (Bracamonte, 2000: 96). La lengua representa el espacio de construcción de ese otro espacio originario. En ese sentido, hay una apropiación absoluta de éste por parte del narrador, quien, por obra de la lengua, introduce su mitología personal en la escritura de la historia del río. De este modo, hay una doble vertiente en tensión ya advertida por Bracamonte y que define la trama textual de El río sin orillas. Por una parte, los tiempos históricos, que son perfectamente ubicados y referidos en el texto y, por otra, una vertiente ontológica, cuyo tiempo es mítico y circular.

Como se puede ver, dentro del recuento histórico, el narrador introduce el mito. La historia del río es también la mitología íntima del río. El reencuentro con el mito personal, como en la imagen inicial del avión en vuelo, es una constante a lo largo del relato. Una de las más significativas ocurre en medio de una parada en el camino a Santa Fe: 
Empecé a pasearme en la penumbra del anochecer, por primera vez después de cinco años de ausencia, en un lugar insignificante, idéntico a todos los otros que lo constituyen, del campo argentino. Recuerdos y sensaciones informuladas, al mero contacto del aire de un anochecer un poco fresco al final del verano, empezaron a insinuarse, indecisos y todavía sin nitidez, en mi interior (Saer, 1991: 76).

Pocas veces Saer habló abiertamente de este sentido del mito. Al menos no de la misma manera en que recurrentemente planteaba la ficción como objeto, hablaba de la selva espesa de lo real o problematizaba la cuestión de los géneros. En alguna ocasión, reflexionó sobre el mito con una apreciación que -me parece- está muy cercana a la forma en que aparece en El río sin orillas. Al mirar la historia con espanto y haciendo eco de cierta afirmación joyceana: "La historia es una pesadilla de la que estoy tratando de despertar", Saer contrapone a esta pesadilla otra forma de comprensión de los acontecimientos:

Despertar de la historia terrible, para abocarme a una contemplación más profunda de la realidad en su conjunto y no meramente la realidad histórica. Una contemplación, digamos, del ser del mundo como una totalidad a través de una experiencia mucho más personal y profunda que la del mero cronista. Desbrozando la experiencia histórica, quiero tener una experiencia esencial de mi situación en el universo, de este conjunto que formamos yo y el universo, a través de lo que Joyce llamaba una epifanía (Saer, 1995: 77).

Se advierte en la epifanía aludida por Saer una dimensión mítica, que se explicita al momento de entender la afirmación joyceana como un intento de llegar a ella: "Entonces lo que quiere decir Joyce es que el camino de la ficción es salir de la historia para 
dirigirse al mito" (Saer, 1995: 78). ¿Cuál es entonces este sentido del mito para Saer? En efecto una experiencia muy personal, más propia y entrańable que la del mero cronista.

Me parece que no de otra manera está planteado el mito personal del autor en la escritura de la historia del río. Pero no para que la comprensión íntima e individualizada hable en nombre de lo verídico, como si usurpara el discurso de la ciencia histórica, sino como otro discurso que no está tanto para negar o afirmar, como para cuestionar eso que se asume por realidad. Es decir, de nuevo la aparición de ese objeto que, como una cuña, se introduce en la representación del mundo, dentro de la historia. Como otra forma que también está implicada en la construcción de la realidad y a la que objeta. $^{7}$

En ese sentido se podría entender la confrontación de la realidad y la ficción en el texto de Saer. No es un recurso gratuito: ¿para qué simular que se relatan sólo hechos verificados si al final se trata de salvar lo ficticio? Se busca premeditadamente esa fricción con la historia, para que, sin que deje de serlo, brinde entera cabida a la ficción y al mito. De modo que el discurso supuestamente unívoco de la ciencia histórica queda problematizado con una narración cargada de subjetividad: "las figuraciones particulares que la constituyen, por ser justamente particulares, como la sucesión empírica, suscitan, más que sentidos claros, enigmas, y no tanto conceptos afirmativos como interrogaciones" (Saer, 2000: 43).

En El río sin orillas es esencial el cuestionamiento del constructo histórico desde lo íntimo de la narración. El pasaje final del libro alrededor del fuego tiene hondas reminiscencias sobre la institución del asado en tanto rito y comunión, pero también alude al

7 "En realidad, a pesar de lo equívoco de sus estatutos sucesivos o simultáneos, la ficción bajo sus modalidades míticas, literarias, científicas o metafóricas, es un discurso que 'informa' lo real, pero no pretende ni representarlo ni acreditarse en él” (Certeau, 1995: 54). 
fuego verbal del contador de historias en torno al cual se reúne la grey. El "tratado imaginario" de Saer busca ese espacio desde el cual narrar una historia común, aunque de otra manera y sin pretender que sea la suya una historia verdadera sino más bien imaginaria y desde el mito personal, historia al fin que comparten todos los hombres.

\section{Bibliografía}

Abbate, Florencia, 2005, "Entrevista a Juan José Saer", El poeta y su trabajo, núm. 20,

pp. 121-126.

Bracamonte, Jorge, 2000, “Lo autobiográfico en la reinvención territorial (sobre un texto

"menor" de Juan José Saer)", en Desde la niebla. Sobre lo autobiográfico en la literatura argentina, María Elena Legaz (coord.), Alción, Córdoba, pp. 85-107.

Certeau, Michel de, 1995, Historia y psicoanálisis entre ciencia y ficción, Universidad

Iberoamericana/ITESO, México.

Krakowski, Edward, 1956, Historia de Rusia, Surco, Barcelona.

Lejeune, Philippe, 1994, El pacto autobiográfico, Megazul/Endymion, Madrid.

Saer, Juan José, 1991, El río sin orillas. Tratado imaginario, Alianza, Buenos Aires. ,1995, "El valor del mito", en La historia y la politica en la

ficción argentina, Leónidas Lamborghini et al., Universidad del Litoral, Santa Fe, pp. 73-86. 
, 2000, "La narración-objeto", en Norte y sur: la narrativa rioplatense desde

México, Rose Corral (ed.), El Colegio de México, México, pp. 3946.

,2004, "El concepto de ficción", en El concepto de ficción, Seix Barral,

Buenos Aires, pp. 9-17.

, 2005, "Razones", El poeta y su trabajo, núm. 20, pp. 43-46.

Tucídides, 1989, en Enciclopedia Hispánica, Enciclopædia Britannica Publishers, Barcelona.

Recibido: 17 de noviembre de 2016 Aceptado: 3 de abril de 2017 